\title{
El padre Brown: la convergencia de la fe y la razón en el relato "La cruz azul" de G. K. Chesterton
}

\author{
Gabriel Quesada Mora \\ Universidad de Costa Rica \\ Editorial PROMESA, Costa Rica
}

\begin{abstract}
Resumen
La primera parte del artículo muestra una semblanza de G. K. Chesterton, su búsqueda intelectual y luego religiosa, y su amor a la verdad y al sentido común en medio de una sociedad moderna muy segura del poder de la razón, del progreso, las matemáticas, las ciencias, etc. En esta indagación, Chesterton va madurando su pensamiento y su manera de abordar los temas de actualidad sin dejar de lado la reflexión de los grandes temas universales. En un segundo momento se comenta el encuentro entre Chesterton y el catolicismo como experiencia viva con la persona de Cristo. Su conversión fue un largo camino con dos fuertes alas: la fe y la razón. Posteriormente, sigue escribiendo apoyado en estos dos pilares y condimentados ahora con un tercero: su fino sentido del humor, su ironía punzante y sin concesiones. Por último, a partir de este recorrido, se analiza el relato "La cruz azul", en la que se presenta al padre Brown evitando el robo de una cruz de zafiros. Se muestran las relaciones entre los temas de la libertad, el bien y el mal, el uso de la razón, la intuición, y la ciencia. Se muestra cómo el conocimiento, las ideas y la experiencia del catolicismo hacen que el padre Brown tenga las armas necesarias para enfrentar de manera elegante y astuta la dinámica del mal. Además, en la última parte, se muestra la finura del padre Brown que sabe distinguir el mal en sí mismo y la calidad inalienable de la persona como ser con dignidad y capaz de cambiar su destino.
\end{abstract}

Palabras claves: G. K. Chesterton, sentido común, búsqueda, persona, libertad, conversión 


\begin{abstract}
The first part of this article shows G. K. Chesterton's, intellectual and religious quest, his love of truth and common sense in the midst of a modern society that relies only in the power, progress, mathematics, science, etc. In this search Chesterton matures his thought and his way to address current issues without neglecting the reflection of the great universal themes. Then I will mention the encounter between Catholicism and Chesterton as a living experience with the person of Christ. His conversion to Catholicism had two strong wings: faith and reason. Henceforth his writing will be supported by these two pillars and seasoned with a third one: his fine sense of humor, his sharp and uncompromising irony. Finally, I shall present the story "The Blue Cross", in which Father Brown prevents the theft of a cross of sapphires, where the relations between the themes of freedom, good and evil, the use of reason, intuition and science are studied. It shows how knowledge, ideas and the experience of Catholicism give Father Brown the necessary tools to deal elegantly with cunning evil weapons. Moreover, in the latter part we see how Father Brown can distinguish evil in itself and the inalienable dignity of the human person being able to change his destiny.
\end{abstract}

Key words: G. K. Chesterton, common sense, person, freedom, conversion

Las cosas muertas pueden ser arrastradas por la corriente, sólo algo vivo puede ir contracorriente. Chesterton

\section{Chesterton: buscador de la ver- dad, la moral y el sentido común}

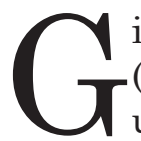

ilbert Keith Chesterton (Londres, 1874-1936) fue uno los escritores más importantes del siglo XX. De él y su literatura una vez dijo Jorge Luis Borges que "quizá ningún escritor me haya deparado tantas horas de felicidad como Chesterton" (p.16). ¿Qué justifica tal afirmación? En Chesterton, convergen de manera extraordinaria la brillantez, la perspicacia y el buen humor. Esta mezcla hizo que tuviera en su vida admiradores y detractores. El sentido del humor que tenía era su manera de relacionarse con el mundo.
Una vez afirmó que "el secreto de la vida reside en la risa y en la humildad". Risa que no es carcajada burlona que busca rebajar la realidad y ofender, sino risa alegre que busca mirar la realidad en su justa dimensión. Una vez en una conferencia dijo "yo no soy tan gordo, lo que sucede es que este micrófono me está amplificando"; en otra oportunidad afirmó que "por lo que respecta a mi peso, nadie lo ha calculado aún" (p.15). Era realmente un hombre de gran estatura y gordo. Como se observa, este humor es una manera de relacionarse con la realidad.

Chesterton fue periodista, novelista, poeta y ensayista. Colaboró con el Daily News y fue director del New Witness. Aunque escribió novela (El hombre que fue jueves, El Napoleón de Notting Hill), se consideró siempre más periodista y ensayista porque, en sus palabras, "a mí me gusta ver las ideas, 
y los conceptos forcejear desnudos, no disfrazados de hombres y mujeres" (p.45). Esta afirmación la comprendemos a la luz de la gran producción periodística y ensayística que por mucho sobrepasa sus contribuciones literarias de relatos, poemas y novelas. Como veremos más adelante, en los relatos del Padre Brown, sí encontraremos conceptos e ideas disfrazados de hombre y mujeres.

La infancia y juventud de Chesterton transcurren en una época en la que están en boga el positivismo cientificista, la teoría de la evolución de las especies de Darwin, el ateísmo, el agnosticismo, la duda metódica e ilimitada, y el relativismo moral; la supremacía de los factores económicos y políticos permean la sociedad inglesa del momento.

En 1892 termina el colegio e ingresa a la universidad. En su Autobiografía dirá que "el ambiente de mi juventud no era solo el ateísmo, sino la ortodoxia atea, y esa postura gozaba de prestigio" (p.17). En el University College de Londres estudia arte, literatura inglesa, francés y latín. Es esta época la que Chesterton llama "mi periodo de locura [...] en la que iba a la deriva, no hacía nada y era incapaz de concentrarme en un trabajo regular. Andaba disperso en un montón de cosas. El pensamiento dominante era nihilista, muy negativo, y yo me hundía cada vez más en una especie de suicidio espiritual" (p.39). Como se observa el fin de siglo ya tenía desencantado a más de uno, las promesas de la ciencia y de la razón habían sido falsas. La Primera Guerra Mundial más adelante llegará a mostrar que el adelanto científicotécnico no iba de la mano con un crecimiento ético y espiritual. Se impuso el poder y la tecnología; no se escucharon las voces que advertían el problema moral y sobrevino la desgracia. Algo parecido piensa Chesterton al reflexionar sobre la conciencia y la moralidad:

En Macbeth aprendemos la gran equivocación que comete un hombre cuando supone que un acto malo le abrirá camino y le conducirá al éxito. Las personas estamos diseñadas para llevar a cabo una conducta coherente entre lo que pensamos y lo que hacemos, y esa deseable coherencia nos obliga a pagar un elevado precio por las incoherencias de nuestros actos. Un precio en forma de sufrimiento moral o psicológico. (Ayllón, p.84)

Vemos aquí la claridad del sentido común de las cosas, la previsión de las consecuencias de los actos humanos, el gran pedido de la libertad humana que exige de la persona una respuesta positiva; cuando no se es fiel a la realidad hay la tentación de hacer falsas promesas, de manipular los hechos y el lenguaje para que parezcan y digan lo que en el momento conviene; pero al final la realidad se mostrará tal cual es y pedirá cuentas a los impostores. Pues bien, Chesterton vive en esta época en la que las promesas de la razón y la ciencia no satisfacen a muchos: la realidad del universo se muestra más allá de los límites de la propia razón humana.

El determinismo era otra de las doctrinas filosóficas de moda a finales del siglo XIX y principios del XX. Para Chesterton, tal propuesta es inconcebible y sin sentido porque desestima en primer término la realidad objetiva de la libertad humana. Además de que si se acepta el determinismo, ya no tienen cabida la responsabilidad ni la ética. Un mundo así es imposible de concebir, 
porque el ser humano es responsable de que se pueden fundar acuerdos perdurables que posibiliten la convivencia social. Si el hombre no es libre y responsable, todo está permitido; sería la supremacía del más fuerte e imperaría la sentencia de Hobbes de que "el hombre es un lobo para el hombre".

Estas filosofías implicaban una especie de desamparo humano: la persona se encuentra indefensa ante fuerzas y causas externas. La supremacía del factor económico no terminaba por explicar las realidades más profundas de la existencia. Al respecto comenta Chesterton que "quien pretenda una interpretación económica de la Historia, nunca podrá explicar el patriotismo de un soldado que muere por su bandera ni el amor de un campesino a su tierra ni la negativa que invoca la objeción de conciencia” (Ayllón, p.87). En definitiva, la economía, la ciencia y la razón son una parte de la realidad, pero no explican total y definitivamente a la persona.

El cambio constante de postura, la ausencia de un referente estable que indicara el norte y la pluralidad de opciones de pensamiento tenían a Chesterton frente a un verdadero mercado de ideologías. Sobre esto comentaba que "el vertiginoso fluir de filosofías desmanteladas nos tenía mareados. Si un día éramos marxistas, al día siguiente éramos nietzscheanos y superhombres, aunque siempre esclavos" (p.85). La mera oferta de pensamiento no hace al hombre libre; acumular opciones no es necesariamente un signo de ejercicio de la libertad. Se es libre cuando de acuerdo con la realidad se compromete la persona entera a un ideal que le sobrepasa. Por el contrario, se es esclavo cuando se siguen ciegamente las ideologías. Hay que buscar la verdad, cuestionarse, teniendo en cuenta los límites propios de la razón humana que es extraordinaria pero limitada. Hay que esforzarse por comprender el universo.

\section{De las filosofías a las personas: el rostro del encuentro}

En 1896 Chesterton conoce a Frances Blogg, quien más tarde -en 1901- sería su esposa. Ella va a ser desde entonces un pilar fundamental en la vida del escritor, quien lo acompañará y lo apoyará en sus diversas actividades intelectuales, sociales y espirituales. En 1900 Chesterton conoce a Hilaire Belloc, historiador que le descubre el pensamiento social cristiano. La gran amistad de ambos les valió ser conocidos como Chesterbelloc; estaban juntos en diversas iniciativas, en las polémicas de los periódicos. En 1909 Chesterton publica su biografía de Bernard Shaw; el hecho es significativo considerando que este hombre era el antagonista por excelencia de Chesterton.

En 1907 Chesterton conoce al padre O’Connor, sacerdote católico, cura párroco de Branford. Le sorprende su inteligencia y su simpatía, su ingenio vestido de inocencia. En efecto, este sacerdote va a ser el modelo a partir del cual Chesterton va a formar a su famoso personaje literario: el padre Brown. El mismo Chesterton confiesa que "surgió en mi mente la vaga idea de dedicar a un fin artístico estos cómicos despropósitos, al mismo tiempo trágicos, y construir una comedia en la que un sacerdote aparentaría no saber nada, conociendo en realidad el crimen mejor que los criminales". Respecto a la Iglesia y al sacerdote, dice Chesterton 
"que la Iglesia Católica estuviera más enterada del bien que yo, era fácil de creer. Que estuviera más enterada del mal, me parecía increíble. El padre O’Connor conocía los horrores del mundo y no se escandalizaba, pues su pertenencia a la Iglesia Católica le hacía depositario de un gran tesoro: la misericordia" (p.54). Poco a poco Chesterton empieza a comprender que una institución que ha caminado más de 1900 años en la historia, algo de experiencia habría de tener sobre el mal; en sus propias palabras comenta:

descubrí que no existe ninguna otra institución estable e inteligente que haya meditado sobre el sentido de la vida durante dos mil años. Su experiencia abarca casi todas las experiencias y, en particular, casi todos los errores. El resultado es un plano en el que están claramente señalados los callejones sin salida y los caminos equivocados. (Ayllón, p.54)

La conversión de Chesterton al catolicismo, en 1922, no fue un asunto de arrebato sentimental o desesperación ante la adversidad. Antes bien fue el resultado de su honesta búsqueda de la verdad. Desde antes de 1908 cuando publica su libro Ortodoxia, ya se va observando que Chesterton no se contenta con explicaciones fáciles o reduccionistas de la realidad del mundo; por eso le impresiona y le atrae la visión cristiana del mundo porque en su propio sistema todo encaja y adquiere sentido desde la lógica del amor de un Dios que es misericordia. Hay un principio claro de lo existente y una finalidad de toda la historia humana: la salvación y la participación libre en el amor de Dios. En este recorrido Chesterton una vez comentó que "hay evolucionistas que no pueden creer en un Dios que hace las cosas de la nada $\mathrm{y}$, en cambio, creen que de la nada han salido todas las cosas. No advierten que el problema del mundo consiste en que no se explica por sí mismo" (p.92). En lógica elemental sería ver manifiesto el principio de causalidad. El efecto sería la existencia del mundo material, la causa estaría previa, existiría antes del mundo. El efecto no produce la causa, sino viceversa. Chesterton le pone nombre a esta causa primera: Dios. Y no es una causa cualquiera sino sumamente ordenada, con leyes y manifestaciones orientadas hacia la vida.

La conversión de Chesterton suscitó en su época un gran revuelo. Si nos atenemos a los hechos veremos que lo menos popular en una Inglaterra anglicana de la década de los veinte era hacer pública una conversión al catolicismo. Pero Chesterton no estaba para mantener una imagen; su fidelidad y su sentido común lo llevaron finalmente a concretar de un modo más fuerte la unidad de vida, hacer converger en su conversión lo que creía y lo que hacía.

\section{El padre Brown: convergencia de la fe y la razón}

La fe y la razón (Fides et ratio) son como las dos alas con las cuales el espíritu humano se eleva hacia la contemplación de la verdad. Juan Pablo II

En los relatos de El candor del padre Brown, G. K. Chesterton presenta a un sacerdote católico que resuelve los más diversos casos de muertes misteriosas y sucesos extraordinarios. Hay que tener presente que en estas historias policiales 
que el detective sea un sacerdote no es un asunto gratuito o marginal; antes bien, precisamente por su condición de sacerdote que usa la razón, la fe y la intuición es que puede acercarse con otra mirada a la realidad de los hechos. Al final del relato "La cruz azul", el ladrón Flambeau está desconcertado al ver que el padre Brown resuelve el caso. Ante este asombro le dice el sacerdote “No se le ha ocurrido a usted pensar que un hombre que casi no hace más que oír los pecados de los demás no puede menos de ser un poco entendido en la materia?" (Chesterton, p.25).

Chesterton, quien reconoce los antecedentes de las historias de Poe y Conan Doyle en sus respectivos personajes Auguste Dupin y Sherlock Holmes, se declara admirador y lector de estos relatos. Hay que comprender que para estos detectives la intuición, el análisis, el método científico, las matemáticas y la deducción son fundamentales para la resolución y conclusión de sus investigaciones. Sin embargo, hay que tener bien claro que un crimen -ya sea asesinato, robo, etc.- no es un problema matemático o un objeto pasivo de estudio. Un crimen es un acto humano en el que interviene en su totalidad la gran complejidad de la persona: libertad, afectividad, inteligencia, corporeidad, espiritualidad. Se comprende entonces que el comportamiento humano no es una ecuación matemática.

Dupin utiliza al extremo la intuición; Holmes, el pensamiento lógico-analítico. El padre Brown combina intuición, lógica y un extraordinario conocimiento del alma humana. Chesterton ya en el primer relato de "La cruz azul" pone de manifiesto que no cree en que el hombre sea solo razón. Al describir al detective oficial Aristide Valentín comenta:
Valentín no era una "máquina pensante", insensata frase, hija del fatalismo y el materialismo modernos [...] era un hombre pensante [...] todos sus éxitos [...] se debían a la lógica. Pero por lo mismo que Valentín entendía el uso de la razón, palpaba sus limitaciones [...] solo el ignorante en cosas de la razón puede creer que se razone sin sólidos e indisputables primeros principios. (Chesterton, p.11)

Chesterton nos presenta no a una máquina sino a una persona. Aristide tiene la facultad de la razón, pero él mismo sabe también que es una facultad limitada. Cuando no hay indicios respaldados por la razón, es momento de intentar otros caminos. "Cuando solo contaba con noticias vagas, Valentín solía tomar un camino y un método que le eran propios" (Chesterton, p.11). Porque es también insensato seguir insistiendo con la razón cuando las pruebas disponibles no son suficientes para elaborar una hipótesis razonable del caso. El caso de la "La cruz azul" amerita entonces poner en marcha otra forma de proceder porque precisamente la lógica ordinaria no da cuenta de lo que está ocurriendo. Por lo anterior, Valentín procede según otro orden: llama a las casas vacías, visita calles bloqueadas y se deja ir por las avenidas que lo alejan de los centros, etc. Estas medidas extremas son combinadas con decisiones de sentido común; al respecto, Valentín comenta que "el hombre tiene que empezar sus investigaciones por algún sitio, y lo mejor era empezar donde otro hombre pudo detenerse" (p.11). En este momento, Valentín sin más indicios vio aquella escalinata y subió al restaurante; ninguna pista lo llevó hasta ahí, pero 
es donde empieza la cadena de sucesos inexplicables: sal en vez de azúcar en el café, la sopa arrojada en la pared, el cambio de los tarjetones de naranjas y nueces, la vidriera rota, el paquete en la confitería... y aquellos dos sacerdotes. Cuando ya están cerca Valentín reconoce al padre Brown y recuerda que este en el tren había comentado que traía un valioso objeto de plata. De inmediato Valentín piensa la hipótesis de que el otro sacerdote es Flambeau que intenta robarle el objeto de plata al ingenuo padre Brown. Valentín llega a una conclusión verdadera: el otro vestido de cura es Flambeau, pero se equivoca en las motivaciones y razones últimas de todo lo que ha observado.

Por su parte, el delincuente en estas primeras historias es el famoso Flambeau: "sus delitos eran siempre hurtos ingeniosos y de alta categoría [...] cada uno podría considerarse una especie inédita del pecado" (p.8). La inteligencia humana se pone al servicio de fines deshonestos. Que un acto sea ingenioso en su industria no implica necesariamente que sea moralmente aceptable. En las primeras líneas del relato "Las estrellas errantes", Flambeau recuerda "el más hermoso crimen que he cometido" (p.65). En esta ocasión, Flambeau puso en marcha toda su inteligencia para urdir el escenario del robo de los diamantes del magnate Sir Leopold Fischer. Esta "hermosura" contrasta con aquella otra hermosura trascendente en la que ocurren los hechos: es Nochebuena. Se pasa de lo aparente al hecho, de la falsedad a la hermosura de la conversión de Flambeau: libremente acepta el consejo del padre Brown de apartarse del mal antes de que este lo consuma por completo.
La descripción que hace Chesterton del padre Brown no es gratuita. Está en la línea del humor, de la paradoja y de la ironía. Nos dice que:

el curita es la esencia misma de aquellos insulsos habitantes de la zona oriental; tenía una cara redonda y roma [...] unos ojos tan vacíos como el mar del Norte [...]. Llevaba una sombrilla enorme, percudida, que a cada rato se le caía. Al parecer no podía distinguir entre los dos extremos de su billete. (p.9)

En definitiva, el padre Brown no sobresale a primera vista, hasta parece algo torpe, pero es precisamente ahí en la persona y la situación menos llamativas donde se va a manifestar luego una gran inteligencia y una gran humanidad. El padre Brown combina la serenidad con una tremenda determinación, escucha, mira, estudia, da consejo y es buen platicador; tiene además un buen sentido del humor. Todo lo anterior en la humildad propia de su oficio de servidor de Dios y de los hombres. Él no está para sobresalir por sus facultades: es un cooperador de la Verdad que busca la salvación de las almas. Resolver los casos es un medio para que brille la luz de la verdad y, con esta luz, conducir a los criminales hacia el bien. El padre Brown es intolerante con el error -robo, asesinato, estafa, extorsión, etc.-; no lo admite porque al igual que Tomás Moro es más amigo de la verdad, pero es tolerante con la persona que se equivoca. Ejemplo de lo anterior es la conversación que tiene con Flambeau al final del relato "Las estrellas errantes": 
Quiero que me los devuelva usted, Flambeau, y quiero que abandone usted esta vida. Todavía tiene usted bastante juventud, buen humor y posibilidades de vida honrada. No crea usted que semejantes riquezas le han de durar mucho si continúa usted así. Los hombres han podido establecer una especie de nivel para el bien. Pero, ¿quién ha sido capaz de establecer el nivel del mal? Ése es un camino que baja y baja incesantemente. (pp.77-78)

El padre Brown es firme frente al error, no maquilla la realidad: Flambeau ha robado los diamantes y debe reintegrarlos. El sacerdote exhorta al ladrón para que en un acto de soberana libertad devuelva él mismo lo hurtado y rectifique. El cura no se queda en la inmediatez del momento, ve hacia el futuro y le expone a Flambeau el peligro de seguir en este camino de maldad. Pero no todo está perdido - no hay determinismos-; la razón, la libertad y el bien hacen posible enderezar el camino y comenzar una nueva vida.

Respecto al método del padre Brown tenemos que es muy sencillo, no hay artificio. En "El secreto del padre Brown" el cura confiesa que:

yo fui el que mató a esas personas [...] yo quise decir, y digo, que me vi a mí mismo cometiendo esos asesinatos. No digo que los ejecutara. Lo que yo quiero decir es que pensé y pensé de qué manera podría un hombre llegar a ser así, hasta que me daba cuenta de que yo mismo era de aquella manera, en todo, menos en aceptar el consentimiento formal de la acción. (p.17)

Se pone de manifiesto que el sacerdote conoce la sustancia humana de lo que está hecho. Sabe de la fragilidad, de la tentación, de los obstáculos. Pero, al mismo tiempo, comprende que el límite del mal puede ser fijado con la respuesta positiva de la libertad humana hacia el bien.

En su caso particular, sí hemos de decir que hay una gran unidad y correspondencia entre las ideas de Chesterton como persona y figura pública y sus personajes literarios. En este caso el cura de Essex es el vocero de muchas de las ideas que Chesterton vertía en sus artículos y ensayos. Por ejemplo, respecto al tema de la razón y la teología, el padre Brown con claridad meridiana le dice a Flambeau -que está vestido de cura- que una de las pistas que lo llevaron a descubrir que no era un sacerdote es que "usted atacó la razón; y eso es de mala teología" (p.25). Para Chesterton como para la Iglesia Católica, la razón no se opone a la fe; antes bien, van juntas en el camino hacia la verdad. Han de ayudarse mutuamente. Al respecto son clarificadoras las palabras de Juan Pablo II en la encíclica Fides et ratio:

No hay, pues, motivo de competitividad alguna entre la razón y la fe: una está dentro de la otra, y cada una tiene su propio espacio de realización [...] El libro de los Proverbios nos sigue orientando en esta dirección al exclamar: «Es gloria de Dios ocultar una cosa, y gloria de los reyes escrutarla» $(25,2)$. Dios y el hombre, cada uno en su respectivo mundo, se encuentran así en una relación única. En Dios está el origen de cada cosa, en Él se encuentra la plenitud del misterio, y ésta es su gloria; al hombre le corresponde la misión de investigar con su razón la verdad, y en esto consiste su grandeza. 
Una teología que tenga en poco a la razón no es fiel a la realidad propia del ser humano como ser racional. Una razón que no considere la fe tendrá una visión parcial de la realidad porque con la sola razón no se explica todo lo existente.

En definitiva, las historias del padre Brown muestran una preocupación por el ser humano. La razón y las demás facultades están al servicio del bien y la verdad. La investigación de los casos es un medio para poner en claridad las más íntimas motivaciones del comportamiento humano.

\section{Nota}

1. Trabajo efectuado en el marco del proyecto "Talleres de capacitación a profesores de español de secundaria de III Ciclo, Proyecto ED-2145 de la Vicerrectoría de Acción Social y del INIE.

\section{Bibliografía}

Ayllón, José R. (comp). Ciudadano Chesterton. Madrid: Ediciones Palabra, 2011. Impreso.

Chesterton, G.K. El candor del padre Brown. Buenos Aires: Editorial Claridad, 1999. Impreso.

--. La inocencia del padre Brown. Madrid: Ediciones Encuentro, 1995. Impreso.

--. Por qué soy Católico. Madrid: El buey mudo, 2011. Impreso.

Domínguez Prieto, Pablo. La crisis de la razón. Conferencia pronunciada el 16 de febrero de 2009, en Madrid. < http:// magnificat.tv/es/node/284>

Juan Pablo II. Fides et ratio. Vaticano: Libreria Editrice Vaticana, 1998. Impreso. 
